\title{
Unilateral sinonasal disease regarding clinical, radiological and pathological features
}

\begin{tabular}{c}
\hline Said Mustafa Said ${ }^{1 *} \quad$ Mahammad Sherwani $^{2}$ \\
\hline Abstract
\end{tabular}

Background and objective: Patient with unilateral nasal pathology is common in clinical practice. A careful history followed by complete otolaryngology examination is mandatory and diagnostic nasal endoscopy by either flexible or by using endoscope. This study aimed to assess patients presented with the unilateral sinonasal disease, regarding clinical features, CT scan findings, and histopathological results.

Methods: A prospective study was completed on 90 patients with unilateral sinonasal disease. The study was conducted at the Otolaryngology Department, Rizgary Teaching Hospital, Erbil city, Iraq, from February 2017 to July 2018. Regarding the pathological result, patients were categorized into two main groups of inflammatory and neoplastic. A biopsy was taken for histopathological confirmation from the patients with nasal mass either under local or under general anesthesia. The patients had been assessed clinically and radiologically.

Results: Chronic rhinosinusitis was found to be the commonest cause of unilateral sinonasal disease followed by antrochoanal Polyp, benign tumor, fungal sinusitis and then malignant tumor in that order. Male gender and right side were predominant. The purulent nasal discharge was the commonest symptom under inflammatory conditions, while nasal bleeding, dental and orbital complained were the main symptoms in neoplastic diseases. Calcifications were noted on CT scan, mainly in patients with fungal sinusitis. Bony erosion and destruction were detected in the malignant tumor.

Conclusion: Chronic rhinosinusitis was the most common cause of unilateral nasal and paranasal disease. Comprehensive evaluations of patient age, presenting symptoms, naso - endoscopic examination, and CT finding help in the diagnosis of unilateral sinus disease. However, histopathological confirmation remains the gold standard for final diagnosis

Keywords: Chronic rhinosinusitis; Unilateral nasal mass; Inflammatory nasal polyposis; Nasal obstruction.

\section{Introduction}

Patient with unilateral nasal symptoms, nasal mass or polyp or sinus opacity is common in clinical practice, a wide range of presenting symptoms like nasal obstruction, nasal discharge, epistaxis, hyposmia, facial pain and swelling, headache, fever, dental pain, ear pain, and fullness may be involved in the clinical feature on presentation. ${ }^{1}$ For proper diagnosis, careful history followed by complete otolaryngology examination by anterior and posterior rhinoscopy and diagnostic nasal endoscopy is the first step in the evaluation of the patients. ${ }^{2}$ Computed tomography (CT) of the paranasal sinuses is now a routine investigative method for patients with sinonasal symptoms that may require surgical intervention. The presence of sinus opacification on CT scans that is resistant to medical treatment or a visible mass on endoscopic examination demands further investigations for an accurate diagnosis, such as biopsy or surgery. ${ }^{3}$ The etiology is usually an inflammatory

${ }^{1}$ Department of General Surgery, College of Medicine, Hawler Medical University, Erbil, Iraq.

2 Rizgary Teaching Hospital, Erbil, Iraq.

* Correspondence: elaf3d@yahoo.com 
disease, which can be managed conservatively with medical treatment with few patients requiring surgical intervention. ${ }^{4}$ Diverse disease processes can lead to unilateral sinus opacification, including acute or chronic rhinosinusitis (CRS), nasal polyposis (NP), allergic or non-allergic fungal sinusitis, mucoceles, and benign or malignant neoplasia. ${ }^{5-9}$ The underlying etiological and predisposing factors and associated conditions of chronic rhinosinusitis varies which include infections like viral, bacterial, fungal and parasitic infections, hypersensitivity in allergy $\lg E$ mediated and non-IgE mediated hypersensitivities, aspirin hypersensitivity with asthma, polyps, and vasomotor factors, other factors like environmental, cold and wet climate and overcrowding, immunodeficiency disease, endocrinal in pregnancy, and hypothyroidism, pollution, mucociliary abnormalities: cystic fibrosis and primary ciliary dysmotility, pollution e.g., chronic irritation from dust, smoke, cigarette smoking, and snuff and also structural defects like deviated nasal septum (DNS), synechia, choanal atresia and osteomeatal complex abnormalities. ${ }^{10}$ In this study, we describe the characteristics of unilateral sinonasal disease by assessing clinical manifestation, radiological finding, and histopathological results in order to better understand the clinical pattern of this disease.

\section{Methods}

A prospective study carried out from February 2017 to July 2018 at Rizgary Teaching Hospital in Erbil, Iraq. The study involved 90 patients who presented with unilateral sinonasal disease. The inclusion criteria included patients aged $13-70$ years with chronic unilateral nasal and paranasal hyperdensity on CT scan. Patients with unilateral nasal symptoms for more than three months and those who presented with suspicious features from the beginning are included in the study. Exclusions criteria included patients' symptoms less than three months, age less than ten years, previous sinus surgery, females who are pregnant or lactating, and patients with known systemic diseases such as cystic fibrosis and Kartagner syndrome. All patient with unilateral sinonasal symptom were included in this study were analyzed by careful history followed by complete otolaryngological examination including detailed nasal examination by anterior and posterior rhinoscopy and diagnostic nasal endoscopy by either flexible or by using rigid Hopkins rod endoscope $4 \mathrm{~mm}$ 0 degree is the first step in the evaluation of studied patients. CT scan for the patients in coronal, axial, and sagittal views were analyzed. Biopsy specimens are obtained by rigid rod Hopkin endoscopy $4 \mathrm{~mm}$ or $2.7 \mathrm{~mm}$ 0-degree. Excisional biopsy was taken from a suspicious disease site by using punch biopsy forceps. According to histopathological results, patients were categorized into inflammatory and neoplastic. The demographic data, clinically, radiological, and pathological study findings were compared and analyzed. Patients age were between $12-65$ years with chronic unilateral nasal and paranasal hyper dense shadow on CT scan were analyzed in this study, Patients with unilateral nasal symptoms for more than 3 months and those who presented with suspicious features from the beginning are included in the study. All patients who had previous sinus surgery and those who were less than twelve years old and patients with; cystic fibrosis, Kartagener syndrome. The preoperative CT findings of the mucosal conditions of the maxillary, anterior ethmoid, posterior ethmoid, sphenoid, and frontal sinuses, and the ostiomeatal complex were evaluated using the Lund-Mackay grading system. The mucosal abnormalities were graded as 0 (no abnormality), 1 (partial opacification), or 2 (total opacification) for each sinus group. The Lund MacKay score classification. The ostiomeatal complexes were scored as 0 (not occluded) or 2 (occluded). The scores ranged from 0 to 12 
because the patients who participated in this study had unilateral sinus disease. In addition to the extent of the disease, pathologic findings such as calcification in the sinuses, bone expansion, and bony erosion or destruction were evaluated. Data were analyzed using the statistical package for the social sciences (version 22). The Chi-square test of association was used to compare proportions. Fisher's exact test was used when the expected count of more than $20 \%$ of the cells of the table was less than 5 . A $P$ value of $\leq 0.05$ $\mathrm{x}$ was considered statistically significant.

\section{Results}

Ninety patients were enrolled in the study. Their mean age was 36 , ranging from 12 to 65 years, as shown in Figure 1. The study group consisted of 48 males and 42 females with a median age at presentation was 36 years. From the total 90 patients, the inflammatory causes of unilateral nasal diseases were $73(81.1 \%)$ compared with the neoplastic group, which was 17 $(18.8 \%)$, as shown in Figure 2.

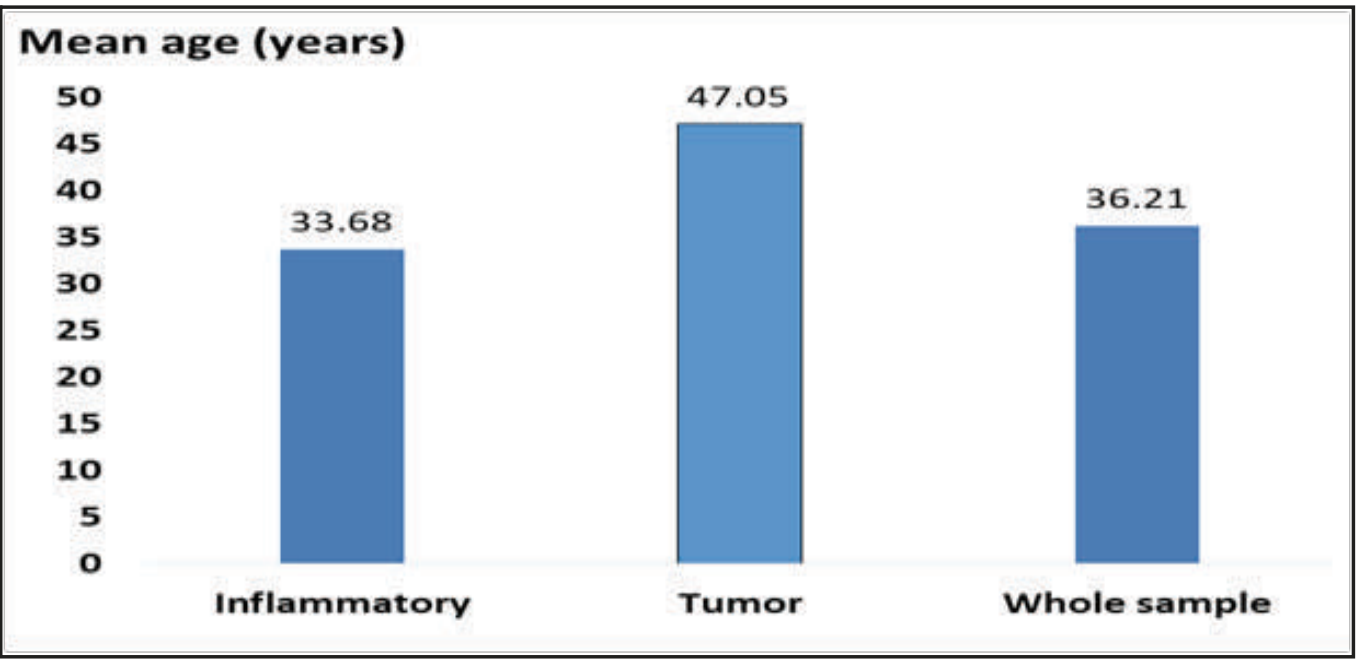

Figure 1: Mean age of patients of both inflammatory and tumor group.

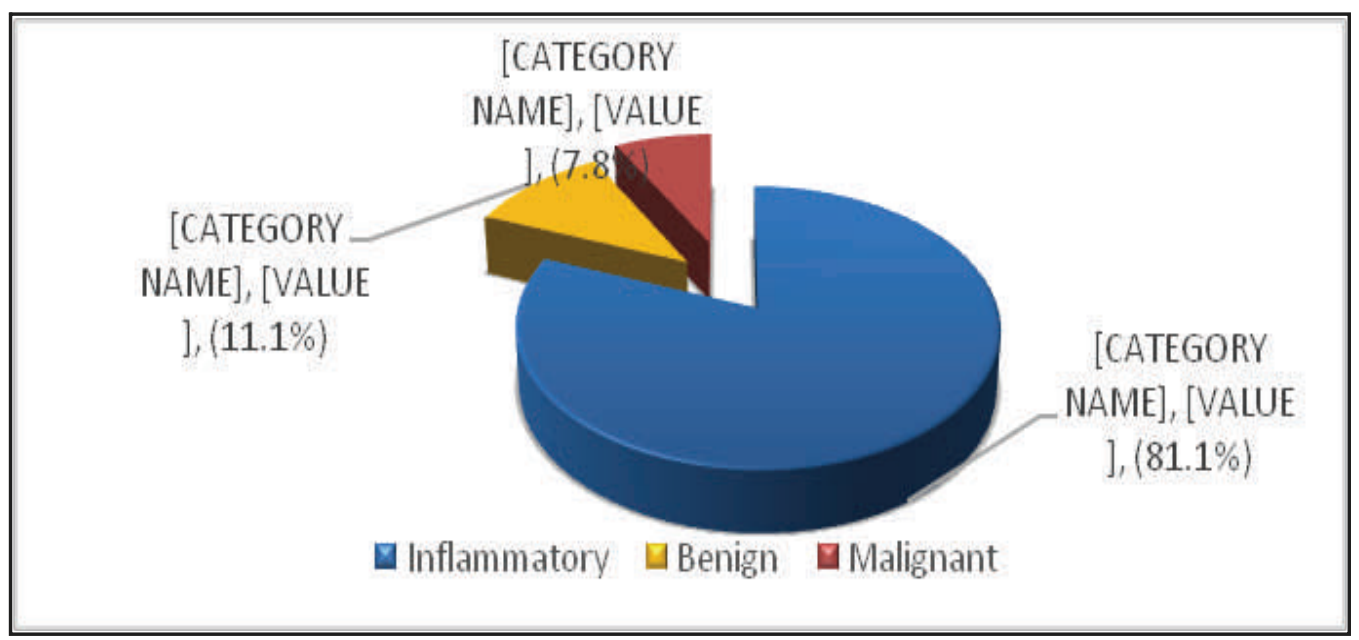

Figure 2: Number of patient distribution in postoperative histopathology. 
Clinical manifestation: About presenting symptoms, nasal obstruction was the predominant feature in both groups $(87.8 \%)$. Majority of inflammatory group 60 of $73(82.2 \%)$ presented with nasal discharge compared with 7 of 17 (41.2\%) in tumor group. Regarding extranasal symptom $36(40 \%)$ patients presented with facial pain, $29(32.2 \%)$ suffered from hyposmia, $20(22.2 \%)$ had epistaxis, $26(28.9 \%)$ complain from headache while regarding dental and orbital complain they presented with $18(20 \%)$ and $12(13.3 \%)$ patients respectively (Table 1 ).

Radiography: On the pre-operative CT scan image, 67 (74.4\%) of patients had obliteration of osteomeatal complex on the table below show that $65(89 \%)$ of the inflammatory group had homogenous intrasinus density compared with 10 $(58.8 \%)$ of the tumor group. The majority of tumor patients had bone expansion $15(88.2 \%)$ and bone erosion $13(76.5 \%)$ compared with $22(30.1 \%)$ and four $(5.5 \%)$ of inflammatory group respectively $(P<0.001)$. The adjacent structures were involved in five $(29.4 \%)$ of tumor patients with two $(2.7 \%)$ of patients in the inflammatory group (Table 2).

Table 1: Clinical manifestation of unilateral sinonasal pathology $(\mathrm{N}=90)$.

\begin{tabular}{lccccccc}
\hline \multirow{2}{*}{ Symptoms } & \multicolumn{2}{c}{$\begin{array}{c}\text { Inflammatory } \\
(\mathbf{n}=\mathbf{7 3 )}\end{array}$} & \multicolumn{2}{c}{$\begin{array}{c}\text { Tumor } \\
(\mathbf{n}=\mathbf{1 7})\end{array}$} & \multicolumn{2}{c}{$\begin{array}{c}\text { Total } \\
(\mathbf{n}=\mathbf{9 0 )}\end{array}$} & P value \\
& No. & $(\mathbf{\%})$ & No. & $(\mathbf{\%})$ & No. & $(\%)$ & \\
\hline Nasal obstruction & 66 & $(90.4)$ & 13 & $(76.5)$ & 79 & $(87.8)$ & 0.209 \\
Nasal discharge & 60 & $(82.2)$ & 7 & $(41.2)$ & 67 & $(74.4)$ & 0.001 \\
Facial pain & 26 & $(35.6)$ & 10 & $(58.8)$ & 36 & $(40.0)$ & 0.079 \\
Hyposmia & 21 & $(28.8)$ & 8 & $(47.1)$ & 29 & $(32.2 .0)$ & 0.146 \\
Epistaxis & 9 & $(12.3)$ & 11 & $(64.7)$ & 20 & $(22.2 .0)$ & $<0.001$ \\
Headache & 19 & $(26.0)$ & 7 & $(41.2)$ & 26 & $(28.9 .0)$ & 0.242 \\
Dental complain & 9 & $(12.3)$ & 9 & $(52.9)$ & 18 & $(20.0)$ & 0.001 \\
Orbital complain & 4 & $(5.5)$ & 8 & $(47.1)$ & 12 & $(13.3)$ & $<0.001$ \\
\hline
\end{tabular}

Table 2: Pre-operative CT scan of unilateral sinonasal pathology.

\begin{tabular}{|c|c|c|c|c|c|c|c|}
\hline \multirow{3}{*}{ CT findings } & \multicolumn{6}{|c|}{ Histo-pathological diagnosis } & \multirow{3}{*}{$P$ value } \\
\hline & \multicolumn{2}{|c|}{$\begin{array}{l}\text { Inflammatory } \\
\quad(n=73)\end{array}$} & \multicolumn{2}{|c|}{$\begin{array}{l}\text { Tumor } \\
(n=17)\end{array}$} & \multicolumn{2}{|c|}{$\begin{array}{c}\text { Total } \\
(\mathrm{n}=90)\end{array}$} & \\
\hline & No. & $(\%)$ & No. & $(\%)$ & No. & (\%) & \\
\hline Obliteration of OMC & 56 & $(76.7)$ & 11 & $(64.7)$ & 67 & $(74.4)$ & 0.353 \\
\hline \multicolumn{8}{|l|}{ Intra-sinus density } \\
\hline Homogeneous & 65 & $(89.0)$ & 10 & $(58.8)$ & 75 & $(83.3)$ & 0.007 \\
\hline Heterogeneous & 8 & $(11.0)$ & 7 & $(41.2)$ & 15 & $(16.7)$ & \\
\hline Bone expansion & 22 & $(30.1)$ & 15 & $(88.2)$ & 37 & $(41.1)$ & $<0.001$ \\
\hline Bone erosion & 4 & $(5.5)$ & 13 & $(76.5)$ & 17 & $(18.9)$ & $<0.001$ \\
\hline Involvement of adjacent structure & 2 & $(2.7)$ & 5 & $(29.4)$ & 7 & $(7.8)$ & 0.002 \\
\hline \multicolumn{8}{|l|}{ LM [Lund MacKay score] } \\
\hline $1-4$ & 24 & $(32.9)$ & 3 & $(17.6)$ & 27 & $(30.0)$ & 0.262 \\
\hline $5-8$ & 40 & $(54.8)$ & 13 & (76.5) & 53 & $(58.9)$ & \\
\hline $9-12$ & 9 & $(12.3)$ & 1 & $(5.9)$ & 10 & $(11.1)$ & \\
\hline
\end{tabular}




\section{Pathologically}

From histopathological condition, chronic rhinosinusitis was diagnosed in 47 of 90 patients (52.2\%) followed by antrochoanal polyp in 18 of 90 (20\%). Eight patients had fungal sinusitis. Benign tumor was found in 10 of $90(11.11 \%)$ of patients, $40 \%$ of the benign tumors were inverted papilloma, $30 \%$ were fibrous dysplasia, $20 \%$ were frontoethmoid mucoceles and $10 \%$ were nasopharyngeal angiofibroma. Malignant neoplasms were found in 7 of 90 $(7.7 \%), 4$ of $7(57.1 \%)$ were SCC, 2 of $7(28 \%)$ had adenocarcinoma and 1 of 7 (14\%) were inverted papilloma with malignant changes (Table 3 )

\section{Discussion}

This study was conducted from April 2016 to January 2018 at Rizgary teaching hospital. The study involved 90 patients who complain of unilateral sinonasal disease. In our study, the majority of sinonasal pathology were chronic rhinosinusitis (52.2\%) 47 of 90 followed by antrochoanal Polyp [18 of 90] (20\%) and benign tumor 10 of $90(10 \%)$ comparable result were found in Satish et al., ${ }^{11}$ Lee, ${ }^{12}$ Lee, ${ }^{13}$ and Salami ${ }^{14}$ studies. The mean age was youngest for antrochoanal polyp 8 out of $18(44 \%)$ their age was less than 20 years of age and oldest for malignant tumor 6 out of $7(85.7 \%)$ their age was above 50 years which was similar to Salami study (2009). ${ }^{14}$ On the other hand, Lee study ${ }^{13}$ found that the mean age was also youngest with antrochoanal polyp, but the oldest with fungal sinusitis. In Satish et al. study ${ }^{11}$, they found that $(55 \%)$ was above 50 years of age in neoplastic group $(P=0.0046)$. On analysis of gender and side of pathology in the present study, the right side and male patients were higher in both groups except in antrochoanal polyp, which shows that the left side higher 11 cases out of $18(61 \%)$. A similar result was found in Salami study (2009), ${ }^{14}$ while in Lee study (2008), found that the male patient was also predominant, but the predominant side was the left. ${ }^{13}$ After analyzing various symptoms of the patients, nasal obstruction found to be the predominant feature in both group 79 of $90(87.8 \%)$, but there is no significant difference between the two groups $(P=0.209)$. The majority of inflammatory group 60 of $73(82.2 \%)$ present with nasal discharge compared with 7 of $17(41.2 \%)$ in tumor group $P$ value (0.001). Similar results were found in Satish et al., ${ }^{11} 35$ out

Table 3: Postoperative histopathology of unilartalsinonasal pathology $(\mathrm{N}=90)$.

\begin{tabular}{lcc}
\hline Histopathological & No. & (\%) \\
\hline Chronic rhinosinusitis & 47 & 52.2 \\
Antrochoanal polyp & 18 & 20 \\
Fungal sinusitis & 8 & 8.8 \\
Inverted papilloma & 4 & $(40.0)$ \\
Fibrous dysplasia & 3 & $(30.0)$ \\
Nasopharyngeal angiofibroma & 1 & $(10.0)$ \\
Frontoethmoid mucoceles & 2 & $(20.0)$ \\
SCC & 4 & $(57.1)$ \\
Adenocarcinoma & 2 & $(28.6)$ \\
IP with malignant change & 1 & $(14.3)$ \\
Total & 90 & $(100.0)$ \\
\hline
\end{tabular}


of $44(79.6 \%)$ were having nasal discharge in the inflammatory group. In the meantime, we found in the present study that epistaxis found in two third of tumor group 11 of 17 $(64.7 \%)$ with only 9 of $73(12.3 \%)$ in the inflammatory group and the $P$ value was $<0.001$. Lee study ${ }^{13}$ and Salami study ${ }^{14}$ found that in the inflammatory group, purulent discharge and foul odor were common, while frequent epistaxis was more common in the neoplastic group. In another study, Trittet al. ${ }^{15}$ in unilateral nasal polyposis found epistaxis to be a symptom that has a significant association with neoplastic pathology. We found also in our study that dental complain 9 of $17(52.9 \%)$ and orbitals complain 8 of $17(47.1 \%)$ compared with 9 of $73(12.3 \%)$ -4 of $73(5.5 \%)$ in inflammatory group $(P=0.001)$ and $(P<0.001)$ respectively. Jeayong Lee study ${ }^{13}$ and Azzam Salami study $^{14}$ Satish et al ${ }^{11}$ also conducted in their studies that facial swelling and exophthalmos were more common in the neoplastic group. The CT scan findings revealed that the highest Lund - MacKay scores in the inflammatory group followed by the neoplastic group, although no significant differences found between the two groups $(P=0.262)$. Salami (2009) found in his study that the mean Lund-Mackay score was highest in chronic rhinosinusitis and lowest in antrochoanal polyp; while it is highest in-patient with a malignant tumor and lowest in antrochoanal polyp in Lee (2008). ${ }^{13}$ In the current study, the majority of tumor patients had bone expansion 15 of $17(88.2 \%)$ and bone erosion 13 of 17 (76.5\%) compared with 22 of $73(30.1 \%)$ and 4 of $73(5.5 \%)$ in the inflammatory group respectively $(P<0.001)$. In Lee, bony erosion was detected in benign tumor 7 of $15(46 \%)$ and malignant tumor 7 of 9 patients $(77.8 \%) .^{13}$ Salami (2009) Bony erosion or destruction was detected mainly in malignant tumors $(100 \%$ of cases), followed by mucor mycosis $(73 \%$ of cases), then benign tumors $(40 \%$ of cases). ${ }^{14}$ About intrasinus density, the heterogeneous changes were obvious in fungal sinusitis, which shows six of eight $(75 \%)$. This result was comparable to Lee et al. study $(2008)^{13}$ which found calcifications within the sinus were observed only in patients with a fungus ball (12 of 18 patients, $66.7 \%$ ) and in Salami study $(2009)^{14}$ calcifications within the sinus were observed mainly in patients with allergic fungal sinusitis, and to a lesser extent in chronic rhinosinusitis with or without nasal polyposis and benign tumors. Also in Yoon et al. ${ }^{16}$ who assessed 510 patients and found that $51 \%$ with fungal sinusitis had intrasinus calcification versus $3 \%$ for non-fungal sinusitis. Moreover, in Chen et al., ${ }^{17}$ intrasinus calcification is often cited as a common finding in fungal sinusitis $(72.2 \%)$ compared with patients with chronic rhinosinusitis (10.9\%). In our study, the inflammatory conditions chronic CRS, either from the bacterial or fungal origin, were the commonest histopathological diagnosis. Inverted papilloma and squamous cell carcinoma were the commonest benign and malignant neoplasm $(57 \%)$ and $(40 \%)$, respectively. Similar results were found in Nair et al. (2013) 4 of 9 (44\%) was inverted papilloma in benign and (33.4\%) 3 of 9 was squamous cell carcinoma in the malignant tumor, also in Lee (2008) the most common pathology was inverted papilloma for benign tumor and squamous cell carcinoma for malignant neoplasia. Ravenna et al. ${ }^{18}$ in 2015 found inverted papilloma was the commonest intermediate tumor recorded in their study. Regarding CT scan changes, we observed that bone erosion was observed in fungal sinusitis 4 of $8(50 \%)$ and benign tumor mainly in mucocel 2 of 2 cases (100\%). This has some similarities with a malignant tumor, but the later show more extensive changes on CT scan. In Lee $(2008)^{13}$ for benign tumors, the most common cause of bony erosion was mucoceles (5 of 7 patients, $71.4 \%$ ). Moreover, in Salami $(2009)^{14}$ in benign tumors, the most common cause of bonyerosion 
was mucoceles, followed by inverted papilloma.

\section{Conclusion}

Chronic rhinosinusitis is the most common unilateral pathology found in our study. Nasal obstruction is the commonest presenting symptom in patients with unilateral nasal mass. Epistaxis with extra nasal symptoms like those that dental and orbital complaints are the commonest features in the malignant tumors. Bone expansion in benign tumors or erosion in the malignant tumors was detected, but it was more extensive in the malignant tumors. Punch biopsy before any surgical intervention can sometimes be very helpful to confirm the diagnosis and to make a plan for treatment unless it was suspicious to be vascular like angiofibroma.

\section{Competing interests}

The authors declare no competing interests.

\section{References}

1. Kaplan BA, Kountakis SE. Diagnosis and pathology of unilateral maxillary sinus opacification with or without evidence of contralateral disease. Laryngoscope 2004; 114:981-5.

2. Suh JD, Chiu AG. Acute and Chronic Sinusitis. In: Lalwani AK, editor. Current Diagnosis and Treatment in Otolaryngology-Head \& Neck Surgery. $3^{\text {rd }}$ ed. New York: Lange McGraw Hills; 2008. P. 291-301.

3. Mohan B. Anatomy and Physiology of Nose and Paranasal Sinuses. In: Bansal $M$, editor. Diseases of Ear, Nose and Throat. New Delhi: Jaypee; 2013. P. 29-42.

4. Youngs R, Evans K, Watson M. The paranasal sinuses - a handbook of applied surgical anatomy. Taylor and Francis; 2006.

5. Jean M. Fungal rhinosinusitis. In: Hodder A. Scott-Brown's Otorhinolaryngology, Head and Neck Surgery. $7^{\text {th }}$ ed. UK:Oxford, Blackwell Publishing; 2008. P. 1508-16.

6. Wolfgang D. Frontal sinus. In: Hodder A. Scott-Brown's Otorhinolaryngology, Head and Neck Surgery. $7^{\text {th }}$ ed. UK: Oxford, Blackwell Publishing; 2008. P. 1500-25.

7. Martinduntiz SL. An Atlas of Imaging of the Paranasal Sinuses, The radiologic appearance of benign inflammatory paranasal sinus disease. $1^{\text {st }}$ ed. London: Lippincott Williams \& Wilkins; 1994. P. 87-110.
8. Gleeson MJ, Jones NS, Burton MJ, Clarke R, Browning G, Luxon N, et al, Scott-Brown's Otorhinolaryngology, Head and Neck Surgery. $7^{\text {th }}$ ed. UK: Oxford, Blackwell Publishing; 2008. P. 1531-7.

9. Ah-See KW. Tumors of the nose and sinuses. In: Hussain SM, editor. Logan turner's diseases of the nose, throat and ear, head and neck surgery. $11^{\text {th }}$ ed. FL, USA: CRS press; 2016. P. 119-30.

10. Vivekananda $S$. Infectious rhinosinusitis. In: Bansal $M$, editor. Diseases of ear, nose and throat. New Delhi: Jaypee; 2013. P. 298-319.

11. Nair S, James E, Awasthi S, Nambiar S, Goyal S. A review of the clinicopathological and radiological features of unilateral nasal mass. Indian J Otolaryngol Head Neck Surg 2013; 65 (Suppl 2):199-204.

12. Lee JY, Kim HK. Primary olfactory neuroblastoma originating from the inferior meatus of the nasal cavity. Am J Otolaryngology 2007; 28:196-200.

13. Lee JY. Unilateral paranasal sinus diseases. Acta Otolaryngological 2008; 128:621-6.

14. Salami A. Unilateral Sinonasal Disease: analysis of the clinical, radiological and pathological features. Journal faculty Med Baghdad 2009; 5:372-5.

15. Tritt S, McMains KC, Kountakis SE. Unilateral nasal polyposis: clinical presentation and pathology. Am J Otolaryngology, Head Neck Med Surgery 2008; 29:230-2.

16. Yoon JH, $\mathrm{Na} \mathrm{DG}$, Byun $\mathrm{HS}$, Koh $\mathrm{YH}$, Chung SK, Dong HJ. Calcification in chronic maxillary sinusitis: comparison of CT findings with histopathologic results. AJNR Am J Neuroradiology 1999; 20:571-4.

17. Chen CM, Su IH, Yew KN. Unilateral paranasal sinusitis detected by routine computed tomography: Analysis of pathology and image findings.J Radiol Sci 2011; 36:99-102.

18. Raveena R, Mahesh SG, Devan PP. A Retrospective Analysis of Sinonasal Masses: A Clinical, Histopathological and Radiological Correlation. IJSR 2015; 4(11):46-8. 